\title{
Cell Cycle Control of Schwann Cell Proliferation: Role of Cyclin- Dependent Kinase-2
}

\author{
Ravi Tikoo, ${ }^{1,2}$ George Zanazzi, ${ }^{3}$ Dov Shiffman,, James Salzer, ${ }^{3}$ and Moses V. Chao ${ }^{2,3}$ \\ ${ }^{1}$ Department of Neurology and Neuroscience, Weill Medical College of Cornell University, New York, New York 10021, \\ 2Skirball Institute of Biomolecular Medicine and '3Department of Cell Biology, New York University School of Medicine, \\ New York, New York 10016, and ${ }^{4}$ CV Therapeutics, Porter Drive, Palo Alto, California 94304
}

Schwann cell proliferation is regulated by multiple growth factors and axonal signals. However, the molecules that control growth arrest of Schwann cells are not well defined. Here we describe regulation of the cyclin-dependent kinase-2 (CDK2) protein, an enzyme that is necessary for the transition from G1 to $S$ phase. Levels of CDK2 protein were elevated in proliferating Schwann cells cultured in serum and forskolin. However, when cells were grown with either serum-free media or at high densities, CDK2 levels declined to low levels. The decrease in CDK2 levels was associated with growth arrest of Schwann cells. The modulation of CDK2 appears to be regulated at the transcriptional level, because CDK2 mRNA levels and its promoter activity both decline during cell cycle arrest. Furthermore, analysis of the CDK2 promoter suggests that Sp1 DNA binding sites are essential for maximal activation in Schwann cells. Together, these data suggest that CDK2 may represent a significant target of developmental signals that regulate Schwann cell proliferation and that this regulation is mediated, in part, through regulation of Sp1 transcriptional activity.

Key words: Schwann cell; proliferation; growth arrest; cyclindependent kinase; cell cycle; DRG
During development of the peripheral nervous system, Schwann cells undergo extensive proliferation, migration, and a series of differentiation steps that lead to a myelin-forming cell. The maturation of a fully myelinating Schwann cell depends on contact and signaling from the axon (Jessen and Mirsky, 1999). At the time of birth, Schwann cells begin to establish a 1:1 relationship with a single axon, followed by investment of axons by the myelin sheath (Martin and Webster, 1973). At the time they initiate myelination, Schwann cells have exited the cell cycle and entered a quiescent state. Several growth factors, including neuregulins, Gas6, and TGF- $\beta$, have been implicated during Schwann cell mitogenesis and differentiation; however, little is known about the intracellular mechanisms that control mitogenesis and growth arrest (Mirsky and Jessen, 1996; Jessen and Mirsky, 1998).

A critical property of Schwann cells is the ability to proliferate as a precursor cell and then progress to a nonmyelinating or myelinating cell phenotype. This ability extends under conditions of nerve injury in which Schwann cells are frequently capable of re-entry into the cell cycle (Scherer and Salzer, 1996). After peripheral nerve lesion, myelin degradation and axonal degeneration are accompanied by Schwann cell proliferation. These events are regulated by growth factors and can be potentiated by agents that elevate cAMP, such as forskolin or cholera toxin. The role of the cell cycle in Schwann cells has not been examined.

The principal components of the cell cycle are represented by a family of protein kinases, termed the cyclin-dependent kinases (CDKs), which coordinate progression through the several phases

Received Dec. 30, 1999; revised March 16, 2000; accepted March 23, 2000.

This work was supported by grants from the National Institutes of Health (R.T., J.S.). We thank Andrew Koff for providing reagents and Naoko Tanese and Angus Wilson for advice.

Correspondence should be addressed to Moses V. Chao, Skirball Institute of Biomolecular Medicine, New York University School of Medicine, 540 First Avenue, New York, NY 10016. E-mail: chao@saturn.med.nyu.edu.

Copyright (C) 2000 Society for Neuroscience $0270-6474 / 00 / 204627-08 \$ 15.00 / 0$ of cell cycle via their regulatory subunits, the cyclins (Kohn, 1999; Roberts, 1999). As essential components of the cell cycle, these protein kinases are tightly regulated by several mechanisms. The CDKs are inactive until they bind to their coactivators, individual cyclin proteins. For the holoenzyme complex to become fully active, the cyclin-CDK complexes must become phosphorylated by the cyclin-CDK activating kinase, CAK (Fisher and Morgan, 1994). Negative regulation takes place by the Cip/Kip proteins (p21, p27, p57) and Ink family of proteins (p16, p18, p19), which act as specific inhibitors of the cyclin-CDK enzyme complex (Nakayama, 1998; Pavletich, 1999). In addition, a serine/threonine phosphatase, cdc25, is capable of removing an inhibitory phosphorylation site present in the CDKs (Morgan, 1997).

The G1-S transition is of particular importance. Previous studies have indicated that both CDK2 and the p27 inhibitor protein are involved in the G1-S progression in glial cells (Durand et al., 1997; Tikoo et al., 1997). Both proteins are expressed during the late G1-S phase transition. Cell cycle arrest in astrocytes and oligodendrocytes is accompanied by a decline in CDK2 protein levels and activity, in addition to an elevation of p27 levels (Casaccia-Bonnefil et al., 1997; Tikoo et al., 1997; Tanaka et al., 1998). The mechanisms by which the cell cycle proteins are regulated during Schwann cell development have not been studied, although transformation of primary Schwann cells has been shown to be accompanied by an elevation in CDK2 levels and activity (Lloyd et al., 1997).

To investigate how the cell cycle is regulated in Schwann cells, we have performed experiments from cells isolated at different developmental ages. Schwann cell proliferation can be regulated by axonal contact (Salzer et al., 1980) and soluble factors (Lemke and Brockes, 1984; Ridley et al., 1989; Davis and Stroobant, 1990), as well as extracellular matrix signals (Colello and Pott, 1997). Several molecules that participate in this process have been identified, including neuregulins, cAMP, ascorbic acid, and the 
SCIP and Krox-20 transcription factors (Monuki et al., 1989; Bermingham et al., 1996; Murphy et al., 1996). Here, we show that the level and activity of the CDK2 protein kinase is a critical regulator of Schwann cell cycle arrest. The cyclin-CDK2 components serve as an important restriction point for entry into $\mathrm{S}$ phase. Further analysis of the regulatory elements of the CDK2 gene indicates that the Sp1 element plays a critical role in establishing the levels of CDK2 mRNA in Schwann cells. These results have implications for Schwann cells during development, as well as during neurodegeneration and injury.

\section{MATERIALS AND METHODS}

Reagents. Antibodies against CDK2, CDK4, cyclin E, Sp1, and p27 were from Santa Cruz Biotechnology (Santa Cruz, CA). Antibody against $\beta$-actin was from Sigma and the antibody against S-100 was from Dako (High Wycombe, UK). Polyclonal antibodies against p75 were directed against the cytoplasmic domain (9992). Recombinant cyclin E was prepared using baculovirus-infected SF9 insect cell lysates overexpressing cyclin E as described previously (Firpo et al., 1994).

Schwann cell culture. Schwann cells were isolated from neonatal postnatal day 3 Sprague Dawley rat pups (Brockes et al., 1979). Cells were maintained in the logarithmic phase of growth in DMEM supplemented with $10 \%$ heat-inactivated fetal calf serum (Life Technologies, Gaithersburg, MD), $2 \mathrm{~mm}$ glutamine, and $100 \mathrm{U} / \mathrm{ml}$ penicillin-streptomycin (Life Technologies), and $2 \mu \mathrm{M}$ forskolin (Sigma).

In certain experiments, cells were cultured under serum-free conditions, using 50\% DMEM, 50\% F-12 Nutrient Mixture (Life Technologies), $2 \mathrm{~mm}$ glutamine, $100 \mathrm{U} / \mathrm{ml}$ penicillin-streptomycin, $5 \mu \mathrm{g} / \mathrm{ml}$ transferrin (Sigma), and $5 \mu \mathrm{g} / \mathrm{ml}$ insulin (Sigma). For Western blotting studies, cells were expanded in $2 \mu \mathrm{M}$ forskolin for several generations to obtain sufficient numbers for these experiments.

Dorsal root ganglion neuronal cultures. Dorsal root ganglion (DRG) neuron cultures were prepared as described previously (Kleitman et al., 1991). Neurons were cultured on ammoniated collagen-coated $60 \mathrm{~mm}$ tissue culture dishes, using 30-40 ganglia per dish, in the presence of "C" medium [DMEM with $10 \%$ fetal bovine serum, $50 \mathrm{ng} / \mathrm{ml}$ NGF (Harlan Bioproducts for Science, Indianapolis, IN), $2 \mathrm{~mm}$ glutamine, and $11 \mathrm{~mm}$ glucose]. The next day, the cultures were treated with $\mathrm{C}_{\mathrm{F}}$ media $(\mathrm{C}$ media plus $2.5 \mu \mathrm{g} / \mathrm{ml}$ fluorodeoxyuridine and $2.5 \mu \mathrm{g} / \mathrm{ml}$ deoxyuridine). The cultures were alternately fed $\mathrm{C}$ or $\mathrm{C}_{\mathrm{F}}$ media for 2.5 weeks to remove non-neuronal cells. The isolated neurons were then used for membrane isolation.

Isolation of membranes. DRG membranes were isolated by a modified version of previously described protocols (Salzer et al., 1980). Neurons were removed from culture dishes using sterile forceps after first washing with ice-cold PBS. The cells were collected in $100 \mu$ lof cold PBS in a 2 $\mathrm{ml}$ Dounce homogenizer (Wheaton Science Products, Millville, NJ). After 40 strokes of homogenization with a tight pestle, the homogenates were collected in a microf uge tube and then spun at $80 \times g$ for $20 \mathrm{~min}$ at $4^{\circ} \mathrm{C}$. The resulting supernatant was placed into $10 \mathrm{ml}$ of ice-cold PBS and centrifuged at $32,000 \times g$, at $4^{\circ} \mathrm{C}$, for $1 \mathrm{hr}$. Supernatant was discarded, and the pellet containing DRG membranes was resuspended in $150 \mu \mathrm{l}$ of PBS, at $4^{\circ} \mathrm{C}$. The yield of protein was quantified by the Bio-Rad (Hercules, CA) protein assay according to the manufacturer's directions.

Schwann cell-DRG explant cocultures. Dorsal root ganglia were dissected from embryonic day 16 rat embryos, as described previously (Salzer and Bunge, 1980). The ganglia were plated directly onto ammoniated collagen-coated, $35 \mathrm{~mm}$ tissue culture dishes (15 DRG explants per dish) and cultured in the presence of $\mathrm{C}$ medium. The next day, the cultures were treated with $\mathrm{C}_{\mathrm{F}}$ media. The cultures were alternately fed $\mathrm{C}$ or $\mathrm{C}_{\mathrm{F}}$ media for 2.5 weeks to remove non-neuronal cells. Approximately 100,000 Schwann cells were added to each dish of sensory neurons. The next day, the cultures were switched to serum-free media and maintained in this media for $3 \mathrm{~d}$ to allow for Schwann cells to repopulate the DRG cells. The DRG neuron-Schwann cell cocultures were then switched to C media, supplemented with $50 \mu \mathrm{g} / \mathrm{ml}$ vitamin C (Sigma). After 3-4 weeks in $\mathrm{C}$ plus vitamin $\mathrm{C}$ media, explant cultures are robustly myelinated. At this time, neuronal somas were excised using a sterile scalpel blade, leaving the remaining neurites to degenerate. Control and lesioned explant cultures were harvested at day 5 after lesion, when Schwann cell proliferation was maximal. Protein extracts were obtained by sonication in ice-cold $60 \mu \mathrm{l}$ of HKM buffer (30 mM HEPES-KOH, $\mathrm{pH}$ 7.4, and $7.5 \mathrm{~mm} \mathrm{MgCl}_{2}$ ).
Sciatic nerve isolation. Sciatic nerves were dissected from adult or neonatal (postnatal days 1-14) Sprague Dawley rats. Adjacent perineurium, blood vessels, and fat tissue were carefully removed, and the nerves were washed with PBS at $4^{\circ} \mathrm{C}$ and then sonicated for $2 \mathrm{~min}$ (VirTis, Gardiner, NY) in HKM buffer. The lysate was centrifuged 30 min at $16,000 \times g$ and $4^{\circ} \mathrm{C}$ to remove the cell pellet, adjusted to $0.1 \mathrm{~N}$ $\mathrm{NaCl}$, and stored at $-70^{\circ} \mathrm{C}$ until use.

Bromodeoxyuridine incorporation. Cells were given a $7 \mathrm{hr}$ pulse with 10 $\mu \mathrm{M}$ bromodeoxyuridine (BrdU) and then fixed for $5 \mathrm{~min}$ in ice-cold acetone/methanol (1:1). After $30 \mathrm{~min}$ in $1 \mathrm{~N} \mathrm{HCl}$, cells were incubated with anti-BrdU antibody (1:1000; Dako) in PBS, $0.3 \%$ Tween 20, and 3\% horse serum at $4^{\circ} \mathrm{C}$ overnight. After $1 \mathrm{hr}$ of incubation at room temperature with biotinylated anti-mouse secondary antibody (1:1000 in PBS; Vector Laboratories, Burlingame, CA), cells were stained using FITCconjugated tertiary antibody (1:100 in PBS; Jackson ImmunoResearch, West Grove, PA).

Western blotting. Cells were detached from culture plates by scraping and then collected in HBSS. Cells were washed with PBS and then resuspended in $100 \mu \mathrm{l}$ of ice-cold HKM buffer, $0.5 \mathrm{~mm}$ dithiothreitol, 2 $\mathrm{mm}$ phenylmethylsulfonyl fluoride, $5 \mu \mathrm{g} / \mathrm{ml}$ leupeptin, and $3.5 \mu \mathrm{g} / \mathrm{ml}$ aprotinin. Cells were lysed by sonication (VirTis) and centrifuged at $16,000 \times g$ to separate the cell pellet. Protein extracts were adjusted to $0.1 \mathrm{~N} \mathrm{NaCl}$ and then stored at $-70^{\circ} \mathrm{C}$.

Protein extracts $(20-100 \mu \mathrm{g} /$ lane $)$ were analyzed by $12.5 \%$ SDSPAGE. Protein was transferred from the gel to a polyvinylidene fluoride membrane by a transfer apparatus at $34 \mathrm{~V}$ for $6 \mathrm{hr}$. The membrane was then blocked with $5 \%$ nonfat milk and incubated with primary antibody against cyclin, $\mathrm{CDK}$, or inhibitor protein. After incubating with an anti-rabbit or anti-mouse horseradish peroxidase-conjugated secondary antibody (Boehringer Mannheim, Indianapolis, IN), protein was visualized using an enhanced chemiluminescence system (Amersham Pharmacia Biotech, Arlington Heights, IL). Densitometric measurements were performed using ImageQuant software (Molecular Dynamics, Sunnyvale, CA).

CDK2 kinase assay. Protein extracts were obtained from nonconfluent, proliferating, or confluent, quiescent Schwann cells, by sonication, as above. The extracts ( $40 \mu \mathrm{g} / \mathrm{sample}$ ) were incubated for $30 \mathrm{~min}$ at $37^{\circ} \mathrm{C}$ in the presence of assembly buffer containing $30 \mathrm{~mm}$ HEPES-KOH, $\mathrm{pH} 7.5$, and $7 \mathrm{mM} \mathrm{MgCl}_{2}$, and with the addition of exogenous recombinant cyclin $\mathrm{E}$ to allow for the formation of cyclin-CDK holoenzyme complexes. Addition of physiological levels of exogenous recombinant cyclin $\mathrm{E}$ during the assembly reaction allowed better detection of the kinase reaction without changing the intrinsic activity of the protein extracts (Koff et al., 1993). Physiological levels of cyclin E were determined by immunoblotting extracts from proliferating Schwann cells against varying amounts of recombinant cyclin E obtained from SF9 insect cell lysates overexpressing these proteins (Firpo et al., 1994). Proliferating Schwann cell extracts were found to contain $15 \mathrm{pg}$ of cyclin E per $50 \mu \mathrm{g}$ of total protein.

The assembled extracts were then subjected to immunoprecipitation in $0.5 \%$ Nonidet P- 40 -radioimmune precipitation buffer $(50 \mathrm{~mm}$ Tris, $\mathrm{pH}$ 7.4, $250 \mathrm{~mm} \mathrm{NaCl}, 0.5 \%$ Nonidet P-40, and $5 \mathrm{~mm}$ EDTA) for $1 \mathrm{hr}$ at $4^{\circ} \mathrm{C}$ in the presence of antibody against CDK2, followed by a $1 \mathrm{hr}$ incubation with immobilized protein A-Sepharose beads (Amersham Pharmacia Biotech). The beads were then washed twice with Nonidet P-40-radioimmune precipitation buffer and four times with kinase assay buffer (20 $\mathrm{mm}$ Tris- $\mathrm{HCl}$, $\mathrm{pH} 7.4,7.5 \mathrm{~mm} \mathrm{MgCl}_{2}$, and $1 \mathrm{~mm}$ dithiothreitol). Phosphorylation of histone $\mathrm{H} 1$ kinase was performed by incubating these beads in a $50 \mu \mathrm{l}$ reaction mixture containing $10 \mu \mathrm{Ci}$ of $\left[\gamma^{-32} \mathrm{P}\right] \mathrm{ATP}$ (DuPont NEN, Boston, MA), $30 \mu \mathrm{M}$ lithium ATP, and $1 \mu \mathrm{g}$ of histone $\mathrm{H} 1$ (Boehringer Mannheim) at $37^{\circ} \mathrm{C}$ for $30 \mathrm{~min}$. After incubation, the samples were boiled in SDS-PAGE sample buffer and then resolved by $12 \%$ SDS-PAGE. The gel was dried and subject to autoradiography. Radiolabeled histone H1 bands were then quantitated using a PhosphorImager (Molecular Dynamics).

Plasmids and transfections. The construction of the full-length CDK2 reporter plasmid, the CDK2 promoter deletions, and the Sp1 mutant reporters were described previously (Shiffman et al., 1996). A cytomegalovirus (CMV)-driven vector (pCMVempty) was from Dr. Naoko Tanese (New York University, New York, NY). The pGL2basic vector was obtained from Promega (Madison, WI).

Transfections were performed on primary Schwann cells plated onto 12 well tissue culture dishes, using the Effectene kit (Qiagen, Hilden, Germany), per the manufacturer's directions. Transfections were performed on cells that were $\sim 75 \%$ confluent, using $200 \mathrm{ng}$ of plasmid per 

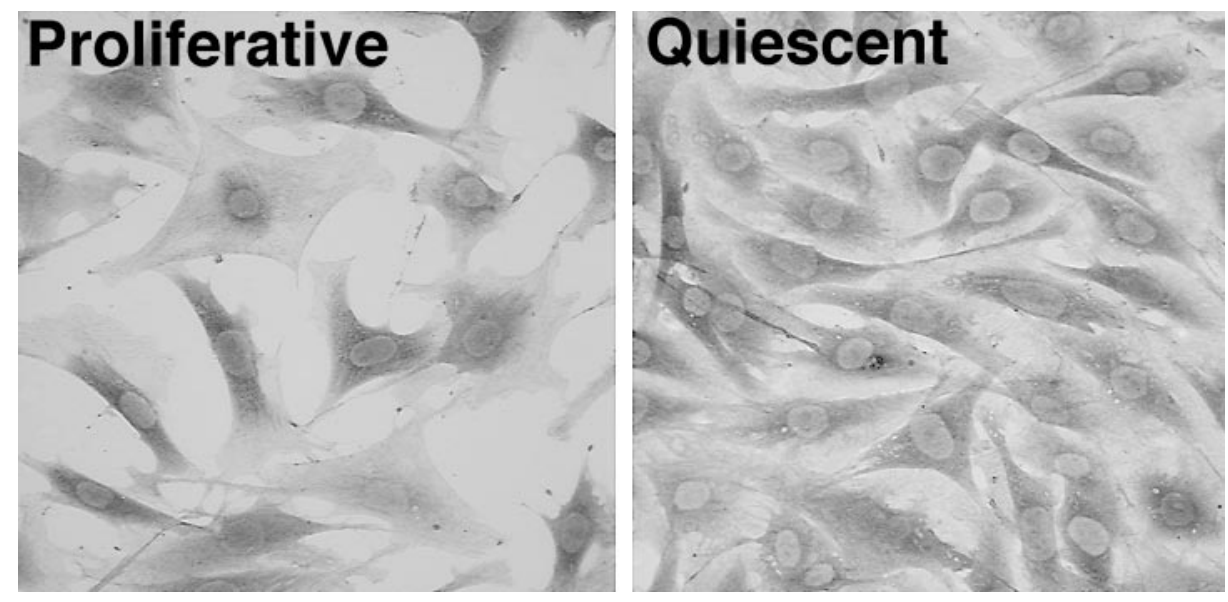

Figure 1. Confluent Schwann cells become growth-arrested. Schwann cells isolated from the rat sciatic nerve were cultured in the presence of $2 \mu \mathrm{M}$ forskolin and $10 \%$ serum. Nonconfluent (Proliferative) and confluent (Quiescent) Schwann cells were each pulsed with BrdU for $7 \mathrm{hr}$. Nonconfluent Schwann cells incorporated $\mathrm{BrdU}(31 \%)$ at the end of this time, whereas $6 \%$ of the confluent cells incorporated BrdU.
Table 1. BrdU incorporation

\begin{tabular}{lcl} 
& $\%$ BrdU+ & SEM \\
\hline Nonconfluent & 30.7 & 5.9 \\
Confluent & 6.4 & 1.3 \\
Serum-free & 11.3 & 1.2 \\
SF + DRG Memb & 20.7 & 0.9 \\
SF + Schwann Memb & 15.4 & 0.3
\end{tabular}

Schwann cells (nonconfluent) were pulsed with BrdU for $7 \mathrm{hr}$. Nonconfluent and confluent Schwann cells were cultured with $10 \%$ serum and $2 \mu \mathrm{m}$ forskolin. Schwann cells grown under serum-free conditions were also cultured in the presence or absence of DRG or Schwann cell membranes (see Materials and Methods for details). The percent of cells incorporating BrdU under each condition is listed. SF, Serum-free.

well, for 24 or $48 \mathrm{hr}$ (depending on the experiment). Cells were scraped from each well, and luciferase activity was obtained by using the Luciferase Reporter Assay System (Promega), according to the manufacturer's directions. Luciferase activity was measured by a luminometer (Lumat; Berthold Inc.) and normalized to the level of protein in each sample.

\section{RESULTS}

\section{CDK2 protein levels are regulated in cultured Schwann cells}

Primary rat Schwann cells cultured in vitro from the postnatal rat sciatic nerve (Brockes et al., 1979) will undergo proliferation in the presence of $2 \mu \mathrm{M}$ forskolin and 10\% serum (Porter et al., 1986). After 10-14 d, contact inhibition ensues and cell proliferation ceases. Schwann cells become quiescent, with $6 \%$ of the cells incorporating BrdU after a $7 \mathrm{hr}$ pulse (Fig. 1; Table 1).

To determine whether cell cycle protein levels are altered in Schwann cells grown under these conditions, we performed Western analysis of protein extracts from proliferating Schwann cells and cells that were grown under confluent, contact-inhibited conditions. Analysis of G1 phase cell cycle proteins (Fig. 2) indicated that the level of CDK2 declined during quiescence, whereas the level of Kip/Cip inhibitor protein p27 increased. In contrast, expression of CDK4 (Fig. 2) and cyclin E (data not shown) were not as significantly altered. CDK2 and p27 function prominently during early and late progression through the G1 phase. This data suggests that cell cycle control may be modulated primarily at the late G1 stage, a point at which cyclin $\mathrm{E} / \mathrm{CDK} 2$ and its inhibitor p27 exert a direct regulatory influence on growth arrest (Scherr and Roberts, 1995).

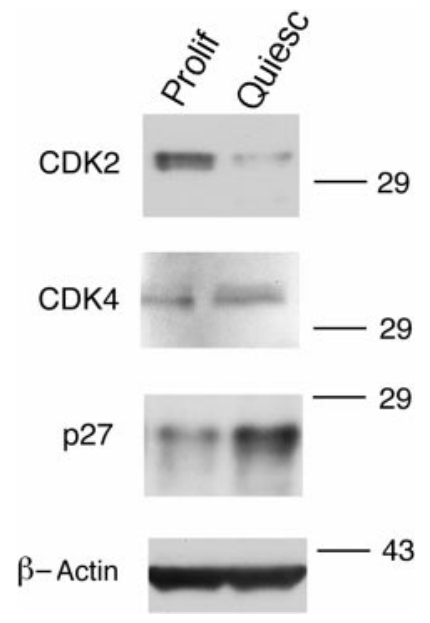

Figure 2. CDK2 protein levels decline in contact-inhibited confluent Schwann cells. Equal amounts of protein extract from either nonconfluent, proliferating (Prolif) or confluent, quiescent (Quiesc) Schwann cells were compared by Western analysis. CDK2 protein levels declined during quiescence, whereas p27 levels increased.

\section{CDK2 kinase activity declines in quiescent Schwann cells}

CDK2 enzymatic activity is essential for entry into the $\mathrm{S}$ phase. Injection of anti-CDK2 or overexpression of dominant negative forms of CDK2 into cells prevents progress into the $\mathrm{S}$ phase of the cell cycle (Pagano et al., 1993). To determine whether a loss of CDK2 kinase activity accompanied Schwann cell growth arrest, we obtained protein extracts from proliferating, nonconfluent cells and compared them with extracts from quiescent, confluent cells. Extracts were immunoprecipitated with anti-CDK2 antibody and then incubated with radiolabeled ATP and histone H1 as a substrate. An abundant level of CDK2-associated histone H1 kinase activity was observed in proliferating Schwann cell extracts and declined dramatically in the quiescent extracts (Fig. 3). Thus, these results suggest that the observed decline in CDK2 protein level during Schwann cell growth arrest may be sufficient to produce this loss of CDK2 kinase activity.

\section{CDK2 protein levels decline in sciatic nerve}

To determine whether the changes observed in culture were also manifest in vivo, we examined the levels of CDK2 during sciatic nerve development. Schwann cell progenitors can be identified from the neural crest at approximately embryonic day 15 (Mirsky 


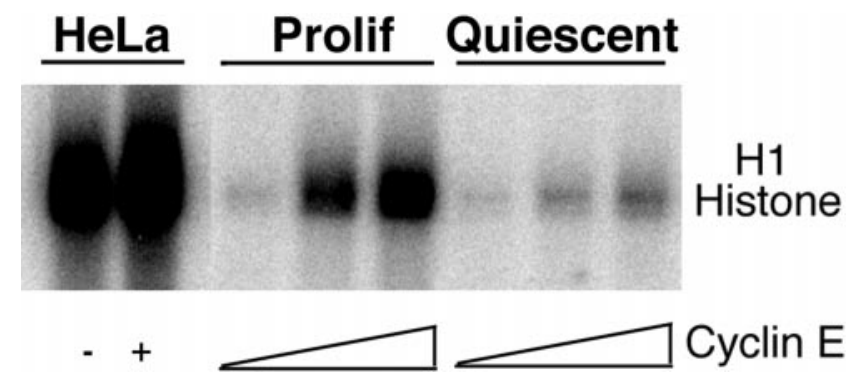

Figure 3. CDK2 kinase activity declines in quiescent Schwann cells. As in Figure 1, protein extracts from proliferating (Prolif) and quiescent (Quiescent) Schwann cells were compared. Extracts were immunoprecipitated with CDK2 antibody, and the resultant complexes were allowed to incubate with $\left[\gamma_{-}{ }^{32} \mathrm{P}\right] \mathrm{ATP}$ and histone $\mathrm{H} 1$ as a substrate. Increasing amounts of exogenous cyclin E $(0,15$, and $60 \mathrm{pg})$ were added to Schwann cell extracts before immunoprecipitation (see Materials and Methods for details). HeLa cell extracts were used as a control.

and Jessen, 1999). Myelination of the rat sciatic nerve begins in the early postnatal period at which time there is an abundance of proliferating Schwann cells. Approximately 27\% BrdU-positive cells were detected at postnatal day 1 from previous measurements (Friede and Samorajski, 1968). Subsequent development and myelination are accompanied by a marked decline in the fraction of proliferating Schwann cells $(<4 \%$ BrdU-positive at day 15 , and $0 \%$ at 16 weeks). The molecular signals that trigger cell cycle arrest are unclear but may be related to a loss of growth factor signaling, exposure to extracellular matrix components, or an intrinsic program of differentiation (Eldridge et al., 1989; Wood et al., 1990; Morrissey et al., 1995).

To examine the expression of cell cycle proteins in Schwann cells as a function of development, sciatic nerves were dissected at several postnatal development ages. Protein lysates were obtained (see Materials and Methods) and subjected to Western analysis. CDK2 protein levels declined in the first 2 postnatal weeks and were absent in the adult (Fig. 4). The p27 inhibitor protein was present at moderate levels in both the early postnatal period and in the adult rat. A transient increase in p27 levels was detected at postnatal day 2 (Fig. $4 A$ ). The observed decline in CDK2 protein levels cannot be attributed to a decline in the density of Schwann cells in the sciatic nerve. Immunoblot analysis of S-100 protein, a marker of Schwann cells, indicated that there was marked expression during this time period. Hence, the decrease in CDK2 levels did not reflect an absence of Schwann cells in sciatic nerve. Also, a decline in the expression of p75 neurotrophin receptor was observed in these sciatic nerve preparations, which is consistent with the downregulation of the $\mathrm{p} 75$ receptor during the period of axon-Schwann cell interactions (Lemke and Chao, 1988; Scherer et al., 1994).

\section{CDK2 is regulated by neuronal membranes}

In contrast to the adult sciatic nerve, axons in the perinatal period are known to have a mitogenic effect upon Schwann cells (Mirsky and Jessen, 1999). To investigate whether axons had an effect on Schwann cell proliferation through CDK2, we treated cultured Schwann cells with a preparation of neuronal membranes. Membrane fractions isolated from DRGs are known to provide a significant mitogenic stimulus to cultured Schwann cells (Salzer et al., 1980). This process is thought to mimic the effect of axons on Schwann cells in vivo and is mediated, in part, by membranebound neuregulin (Levi et al., 1995; Morrissey et al., 1995).

Membranes were isolated from purified cultures of DRG neu-

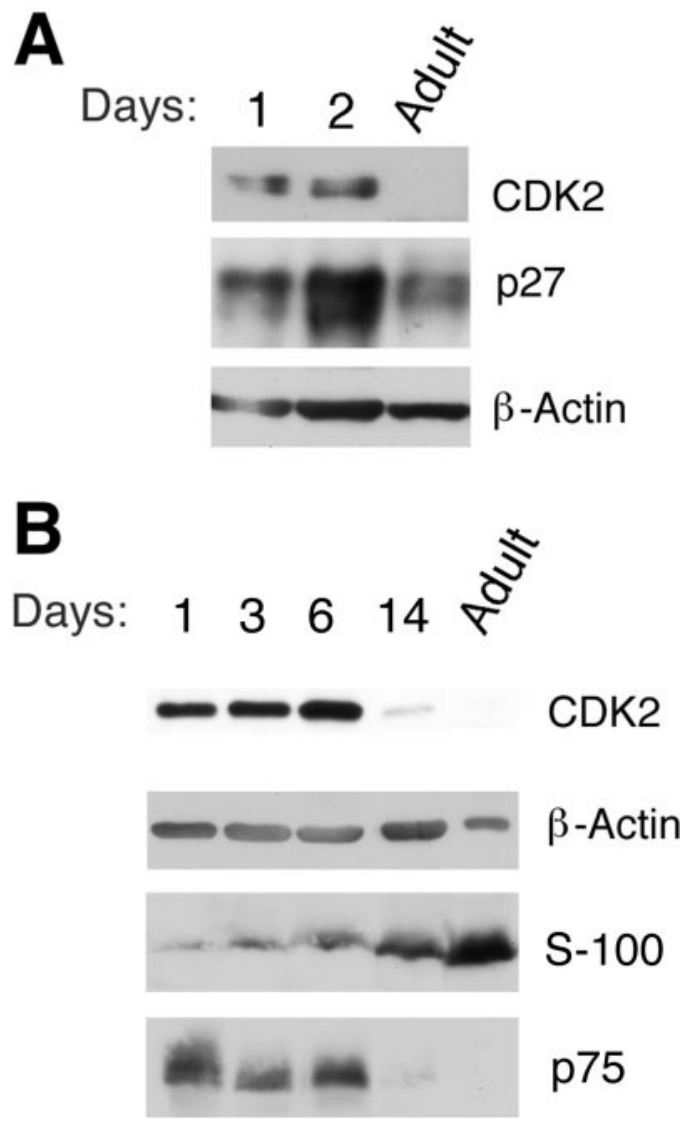

Figure 4. CDK2 levels decline during sciatic nerve development. Extracts were obtained from the rat sciatic nerve at postnatal days 1-14 (1, $2,3,6,14)$ and in the adult rat $($ Adult $)$ and were subject to Western analysis to determine the levels of CDK2 protein. The decline of CDK2 protein correlated with the exit of Schwann cells from the cell cycle in the developing nerve. Levels of the p27 inhibitor protein increased transiently at postnatal day 2 . The levels of $\beta$-actin, p75 neurotrophin receptor, and $\mathrm{S}-100$ protein during this developmental time frame were also monitored by Western blot analysis.

rons (see Materials and Methods). Schwann cells were then treated for $24 \mathrm{hr}$ with DRG membranes. Protein extracts obtained from cells treated under such conditions were compared with extracts from untreated cells. A greater number of Schwann cells treated with membranes from DRGs incorporated BrdU ( $21 \%$ ) compared with $11 \%$ of cells that were not treated. Western analysis indicated that CDK2 protein levels increased significantly in the presence of neurite membranes (Fig. 5A). Densitometric analysis indicated an increase between twofold and sixfold in CDK2 protein $(n=4)$. Furthermore, the effect of membrane treatment on CDK2 levels exhibited a dose-dependent response (Fig. 5B).

Although axonal-glial contact is thought to be a primary mechanism regulating cell cycle proliferation in developing Schwann cells, diff usible factors may be of greater significance in modulating proliferation after nerve degeneration (Wen et al., 1994; Einheber et al., 1995). To determine how de-differentiating Schwann cells re-enter the cell cycle, we used an in vitro model of Wallerian degeneration (Salzer and Bunge, 1980; FernandezValle et al., 1995).

We established primary myelinating Schwann cell-DRG cocultures (Salzer et al., 1980). Under these conditions, Schwann cells are growth arrested and sensory neurons display extensive 


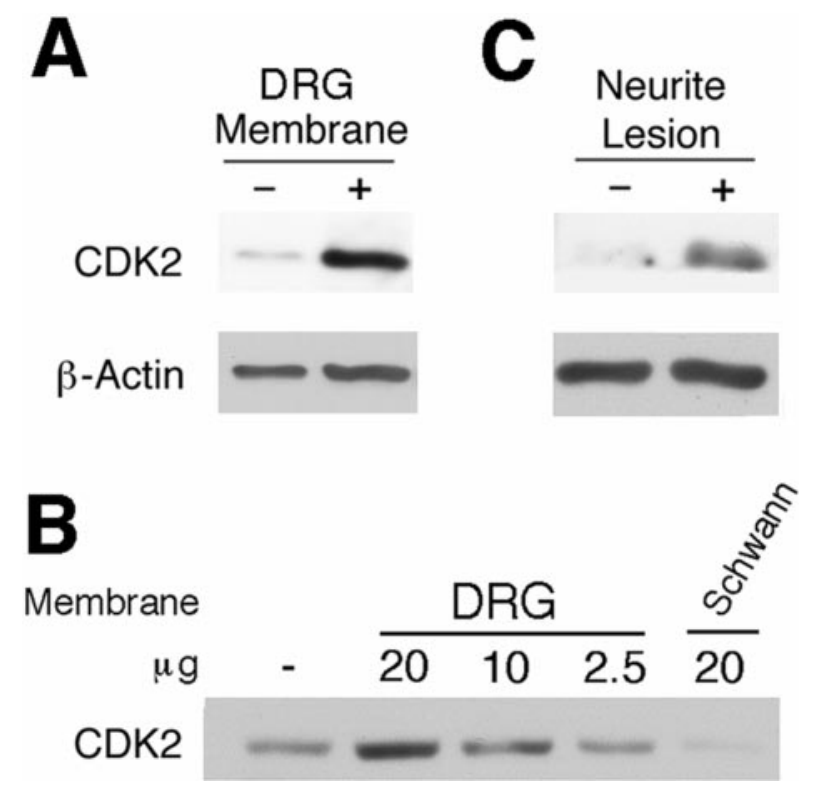

Figure 5. Regulation of CDK2 by neuronal membranes and lesion. $A$, Nonconfluent Schwann cells cultured in serum-free media were treated with (+) or without (-) $20 \mu \mathrm{g}$ of membrane isolated from DRG neurons. After $24 \mathrm{hr}$ of treatment, Schwann cells were harvested and subjected to Western blotting to determine the relative level of CDK2 protein. $B$, Schwann cells treated with increasing amounts of DRG membrane $(2.5-20 \mu \mathrm{g})$ displayed a dose-dependent increase in CDK2 levels. Schwann cell membranes did not have an activating effect. $C$, Neurites from mature, myelinated DRG explant cultures were lesioned, such that distal neurite processes degenerated. Five days after lesion (+), during maximal Schwann cell proliferation, cultures were harvested and the level of CDK2 protein was assessed by Western blotting. Unlesioned cultures $(-)$ were used as controls.

neuritic outgrowth. The somas from each DRG culture were excised with a scalpel, leaving behind the Schwann cells and neuronal processes. Five days after this lesion, Schwann cell proliferation is observed, accompanied by substantial demyelination (Salzer et al., 1980). We isolated protein lysates from the lesioned and untreated cultures and measured the level of CDK2 protein. Western analysis of extracts showed that high levels of CDK2 protein were present in lesioned cocultures compared with extracts from nonlesioned cocultures (Fig. 5C). A twofold to fivefold increase in CDK2 levels was detected by densitometric measurements $(n=4)$. Together, these results indicate that Schwann cell proliferation may be regulated by neuronal membranes or nerve injury by modulating the levels and activity of CDK2.

\section{CDK2 expression is transcriptionally regulated}

To investigate the mechanism of CDK2 downregulation, we measured the steady-state levels of CDK2 mRNA in proliferating and quiescent Schwann cells. Using a cDNA probe for CDK2, Northern blotting revealed that there was a significant level of CDK2 mRNA in proliferating Schwann cells that was markedly decreased in confluent cultures of quiescent cells (Fig. 6). The decline in CDK2 protein levels in Schwann cells suggested that transcriptional regulation of CDK2 may underlie the loss of CDK2 kinase activity during growth arrest.

The levels of CDK2 mRNA can potentially be controlled at the transcriptional or post-transcriptional levels. To test whether the CDK2 gene promoter may be responsible for the regulation of CDK2 levels, we investigated whether the activity of the CDK2

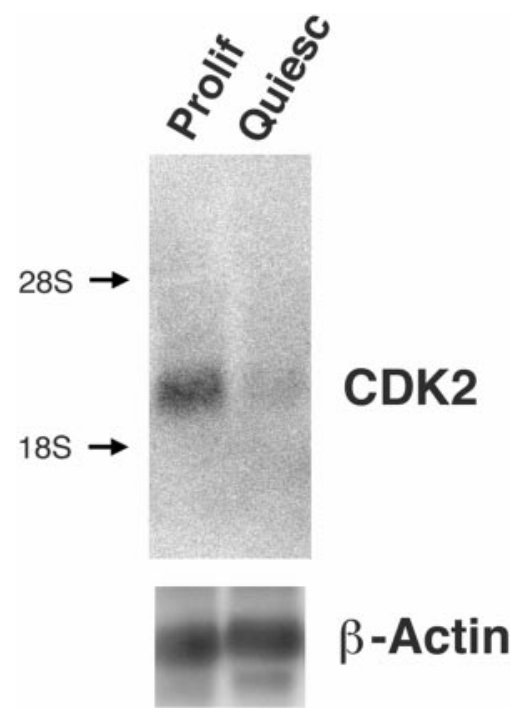

Figure 6. CDK2 mRNA declines in quiescent Schwann cells. Equal amounts of RNA from nonconfluent, proliferating (Prolif) Schwann cells and contact-inhibited, quiescent (Quiesc) Schwann cells were compared by Northern analysis, using CDK2 and $\beta$-actin (loading control) probes.

promoter in Schwann cells was differentially modulated by the addition of neurite membranes and by the presence of serum.

The CDK2 promoter was isolated previously and subcloned into the pGL2basic vector, which uses the firefly luciferase gene as a reporter (Shiffman et al., 1996). We initially transfected the CDK2-luciferase reporter plasmid into nonconfluent Schwann cells for $24 \mathrm{hr}$, cultured in $10 \%$ fetal calf serum. The next day, the cells were cultured under (1) serum-free conditions, (2) in the presence of neurite membranes, or (3) in the presence of $10 \%$ serum and $2 \mu \mathrm{M}$ forskolin, for an additional $24 \mathrm{hr}$. Protein extracts were then obtained and analyzed for the level of CDK2-luciferase activity (see Materials and Methods).

Extracts from quiescent cells cultured under serum-free conditions displayed low levels of CDK2 promoter activity (Fig. 7B). Extracts purified from proliferating cells cultured with serum and forskolin displayed high levels of CDK2 promoter activity. The level of CDK2 promoter activity was consistent with the proliferative state of the Schwann cells, as measured by BrdU incorporation (Table 1). Treatment with DRG membranes gave a slightly higher level of promoter activity than serum-free conditions, suggesting that the CDK2 promoter can be responsive to exogenous stimuli. The reason serum activated the CDK2 promoter to a greater extent than neuronal membranes is unclear but may reflect the possibility that negative feedback mechanisms are activated by serum as well. Together, the decline in mRNA levels and the decline in promoter activity in quiescent Schwann cells suggests that CDK2 may be transcriptionally regulated by developmental signals, as a means of inducing these cells to exit the cell cycle.

\section{Sequences in the CDK2 promoter are essential for CDK2 promoter activity}

Growth-promoting signals can regulate Schwann cell proliferation through diverse signaling pathways. To begin to understand how these signals may influence CDK2 expression, we sought to understand the regulation of the CDK2 gene by analyzing the activity of its promoter sequence.

The activities of several deletion and mutant CDK2 promoter 


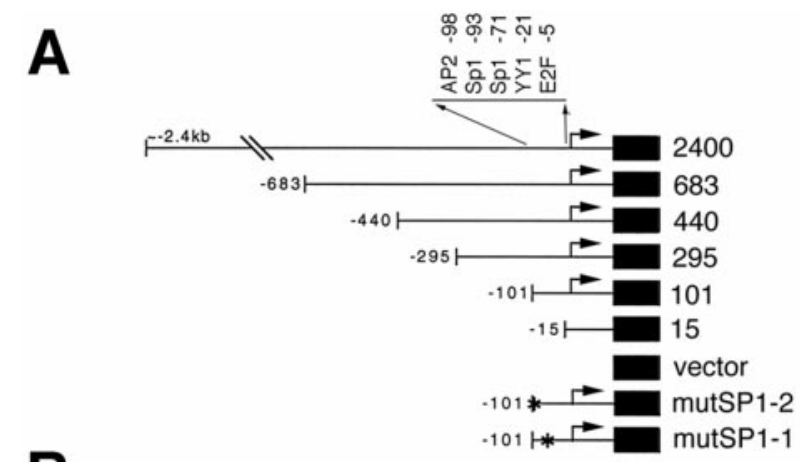

B
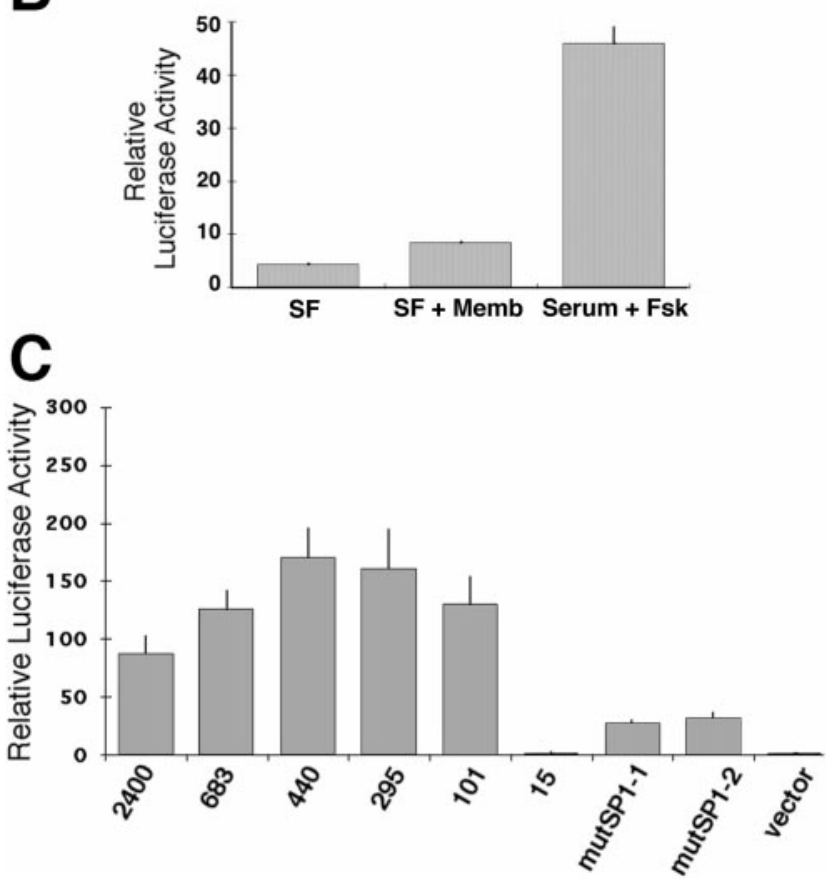

Figure 7. CDK2 promoter activity in proliferating Schwann cells. A, Diagram of the CDK2 reporter plasmids. The plasmids are named according to the length of promoter DNA that is retained. -2400 is the full-length CDK2 promoter, whereas promoter deletions $-683,-440$, $-295,-101$, and -15 retain the proximal $683,440,295,101$, and 15 bp of the promoter. mutSP1-1 and mutSP1-2 contain mutations in the first and second Sp1 sites, respectively. Several consensus sites, including AP2, Sp1, YY1, and E2F are present in the proximal $100 \mathrm{bp}$ of the CDK2 promoter. $B$, The CDK2 promoter is activated during Schwann cell proliferation. Nonconfluent Schwann cells were initially transfected with the full-length CDK2 reporter $(-2400)$ and subsequently cultured for the next $24 \mathrm{hr}$ either under serum-free $(S F)$ conditions to induce growth arrest or with $8 \mu \mathrm{g}$ of DRG neurite membrane $(S F+M e m b)$ or $10 \%$ serum and $2 \mu \mathrm{M}$ forskolin (Serum + FSK) to induce proliferation. C, The proximal $100 \mathrm{bp}$ of the CDK2 promoter is essential for activation. Nonconfluent proliferating Schwann cells cultured in serum and forskolin were transfected with the full-length CDK2 promoter $(-2400)$, promoter deletions $(-683$, $-440,-295,-101$, and -15$)$, promoter Sp1 site mutants (mutSP1-1 and mutSP1-2), or the empty pGL2basic vector (vector) for $48 \mathrm{hr}$. CDK2 promoter activity was absent in deletion -15 , whereas significant activity was retained in deletion -101 . The full-length reporter exhibited approximately one-half of the activity of deletion -440. Mutation of either Sp1 site resulted in a sixfold decrease in promoter activity. Luciferase activity was normalized in each trial, such that activity from the pGL2basic vector alone was made equivalent to one unit.

constructs were analyzed under conditions promoting Schwann cell proliferation (Fig. $7 A$ ). Schwann cells cultured in $10 \%$ fetal calf serum and $2 \mu \mathrm{M}$ forskolin were transfected with the full- length CDK2 promoter (2400), promoter deletions ( $-683,-440$, $-295,-101$, and -15 ), or promoter Sp1 site mutants (mutSP1-1 and mutSP1-2, which contained mutations in the first and second Sp1 sites, respectively). Sp1 protein does not bind to these mutant CDK2 sequences (Shiffman et al., 1996).

CDK2 promoter activity was abundant in the full-length CDK2 promoter, as well as deletions $-683,-440,-295$, and -101 (Fig. 7C). However, CDK2 activity declined approximately sixfold after mutation of either of the Sp1 sites. Deletion of the CDK2 promoter past the proximal $100 \mathrm{bp}$ (deletion 15) resulted in complete loss of promoter activity.

These data indicate that the proximal $100 \mathrm{bp}$ of the CDK2 promoter appears to be essential for expression of CDK2 in Schwann cells. Furthermore, the two Sp1 sites each seem to have a significant effect, because CDK2 activity declined markedly when these sites were mutated. However, other sites within this 100 bp region, such as the YY1 element, may also be involved in regulating CDK2 activity, because the CDK2 promoter with the Sp1 site mutation did not decline completely to baseline levels.

Interestingly, the full-length CDK2 promoter (-2400) displayed approximately one-half the level of activity of promoter deletion -440 , suggesting that there may be repressor elements present upstream of the proximal $300 \mathrm{bp}$ of the promoter that are capable of inhibiting CDK2 transcription. Thus, Schwann cell CDK2 transcription may be modulated by regulating the activator sites in the proximal $100 \mathrm{bp}$ of the promoter or by regulating putative repressor sites present at more upstream sites. The Sp1 transcription factor may play a direct role in the activity of the CDK2 promoter.

\section{DISCUSSION}

Schwann cell proliferation is regulated by many environmental signals. Here we have shown that cell cycle control of Schwann cells is tightly correlated with the CDK2 enzyme, a key component of the machinery that controls entry into $\mathrm{S}$ phase. Early in development during Schwann cell migration, mitogenic signals are derived from neuronally derived neuregulins (Morrissey et al., 1995). In a cell culture model, we show that treatment of Schwann cells with neurite membranes also can lead to increased cellular division, which is accompanied by elevated levels of CDK2 protein. Further development of Schwann cells is characterized by cell cycle arrest and myelination of axons. In the postnatal sciatic nerve, Schwann cell growth arrest is correlated with a decline in $\mathrm{CDK} 2$ protein levels.

Upon completion of development, nerve injury can have dramatic effects on adult Schwann cells. As the distal nerve undergoes Wallerian degeneration, Schwann cells downregulate myelin synthesis, upregulate neurotrophic factor expression, and re-enter the cell cycle, all to prepare the local environment for regeneration. We show in an in vitro model of Wallerian degeneration that CDK2 protein levels become elevated after lesioning of neurites in Schwann cell-DRG cocultures. The regulation of CDK2 protein in Schwann cells under proliferative and quiescent conditions suggests that CDK2 may itself be a primary target of developmental signals that regulate Schwann cell proliferation.

\section{CDK2 promoter activity is downregulated during Schwann cell development}

Cyclin-dependent kinase activity is capable of being regulated by several post-transcriptional mechanisms, including phosphorylation and protein-protein interactions. The experimental results obtained here suggest that CDK2 gene transcription may be a 
direct target of developmental signals. Consistent with this idea, we show that CDK2 mRNA levels decline dramatically in growtharrested Schwann cells compared with proliferating Schwann cells. Furthermore, CDK2 promoter activity declines significantly in growth arrested Schwann cells. Together, these data argue that a decline in CDK2 transcription accompanies Schwann cell growth arrest.

To understand better how normal developmental signals may influence transcription, we have undertaken a study of the CDK2 promoter in Schwann cells. We find that the proximal $100 \mathrm{bp}$ of the CDK2 promoter, and in particular its Sp1 binding sites, are highly significant in regulating $\mathrm{CDK} 2$ promoter activity. Mutation of the two proximal Sp1 sites individually leads to a sixfold decline in promoter activity. Because the promoter activity did not decline to baseline levels, additional modes of regulation are probably also involved in transcription of the CDK2 gene. This includes a repressor activity upstream of the promoter and other transcription factors, such as YY1. Further analysis is necessary to establish the importance of these factors.

$\mathrm{Sp} 1$ is an ubiquitously expressed transcriptional activator that is a member of the Kruppel-like zinc-finger transcription factor family. The binding sites for Sp1 are found in many promoter structures (Turner and Crossley, 1999). Somewhat paradoxically, Sp1 sites are essential for the activities of cell cycle activators, such as cyclin D2 and D3 (Brooks et al., 1996), as well as inhibitors such as p21 (Yan and Ziff, 1997). We have analyzed the level of Sp1 present in proliferating and quiescent Schwann cells. Western blotting revealed that Schwann cell extracts from proliferating cells displayed a higher level of Sp1 protein than in quiescent extracts (data not shown). Thus, a modulation of Sp1 protein levels may also contribute to changes in activity of the CDK2 promoter. Further transfection experiments with Sp1 and other transcription factors will be necessary to define all the elements required for activation of the CDK2 promoter in Schwann cells.

There is evidence that developmental regulation of CDK2 may be a more widespread process. Cardiac, renal, myeloid, melanocyte, and keratinocyte cell differentiation are characterized by a significant loss of CDK2 expression (Burger et al., 1994; Horiguchi-Yamada et al., 1994; Rieber and Rieber, 1994; Park et al., 1997; Kim et al., 1998; Martinez et al., 1999). Furthermore, the level of CDK2 is downregulated during postnatal development of the CNS (Casaccia-Bonnefil et al., 1999). It is likely that extracellular signals converge upon CDK2 activity to modulate the proliferative capacity of Schwann cells. Our data suggests that the CDK2 enzyme may represent a significant transcriptional target of developmental signals that regulate Schwann cell proliferation, through the action of the Sp1 transcription factor.

\section{REFERENCES}

Bermingham Jr JR, Scherer SS, O’Connell S, Arroyo E, Kalla KA, Powell FL, Rosenfeld MG (1996) Tst-1/Oct-6/SCIP regulates a unique step in peripheral myelination and is required for normal respiration. Genes Dev 10:1751-1762.

Brockes JP, Fields KL, Raff MC (1979) Studies on cultured rat Schwann cells. I. Establishment of purified populations from cultures of peripheral nerve. Brain Res 165:105-118.

Brooks AR, Shiffman D, Chan CS, Brooks EE, Milner PG (1996) Functional analysis of the human cyclin D2 and cyclin D3 promoters. J Biol Chem 271:9090-9099.

Burger C, Wick M, Muller R (1994) Lineage-specific regulation of cell cycle gene expression in differentiating myeloid cells. J Cell Sci 107:2047-2054.

Casaccia-Bonnefil P, Tikoo R, Kiyokawa H, Friedrich Jr V, Chao M, Koff
A (1997) Oligodendrocyte precursor differentiation is perturbed in the absence of the cyclin dependent kinase inhibitor p27Kip1. Genes Dev 11:2335-2346.

Casaccia-Bonnefil P, Hardy RJ, Teng KK, Levine JM, Koff A, Chao MV (1999) Loss of p27Kip1 function results in increased proliferative capacity of oligodendrocyte progenitors but unaltered timing of differentiation. Development 126:4027-4037.

Colello RJ, Pott U (1997) Signals that initiate myelination in the developing mammalian nervous system. Mol Neurobiol 15:83-100.

Davis JB, Stroobant P (1990) Platelet-derived growth factors and fibroblast growth factors are mitogens for rat Schwann cells. J Cell Biol 110:1353-1360.

Durand B, Gao FB, Raff M (1997) Accumulation of the cyclindependent kinase inhibitor $\mathrm{p} 27 / \mathrm{Kip} 1$ and the timing of oligodendrocyte differentiation. EMBO J 16:306-317.

Einheber S, Hannocks MJ, Metz CN, Rifkin DB, Salzer JL (1995) Transforming growth factor beta 1 regulates axon/Schwann cell interactions. J Cell Biol 129:443-458.

Eldridge CF, Bunge MB, Bunge RP (1989) Differentiation of axonrelated Schwann cells in vitro. II. Control of myelin formation by basal lamina. J Neurosci 9:625-638.

Fernandez-Valle C, Bunge RP, Bunge MB (1995) Schwann cells degrade myelin and proliferate in the absence of macrophages: evidence from in vitro studies of Wallerian degeneration. J Neurocytol 24:667-679.

Firpo EJ, Koff A, Solomon MJ, Roberts JM (1994) Inactivation of a $\mathrm{Cdk} 2$ inhibitor during interleukin 2-induced proliferation of human $\mathrm{T}$ lymphocytes. Mol Cell Biol 14:4889-4901.

Fisher RP, Morgan DO (1994) A novel cyclin associates with MO15/ CDK7 to form the CDK activating kinase. Cell 78:713-724.

Friede RL, Samorajski T (1968) Myelin formation in the sciatic nerve of the rat. A quantitative electron microscopic, histochemical and radioautographic study. J Neuropathol Exp Neurol 27:546-570.

Horiguchi-Yamada J, Yamada H, Nakada S, Ochi K, Nemoto T (1994) Changes of G1 cyclins, cdk2, and cyclin A during the differentiation of HL60 cells induced by TPA. Mol Cell Biochem 132:31-37.

Jessen KR, Mirsky R (1998) Origin and early development of Schwann cells. Microsc Res Tech 41:393-402.

Jessen KR, Mirsky R (1999) Schwann cells and their precursors emerge as major regulators of nerve development. Trends Neurosci 22:402-410.

Kim SO, Katz S, Pelech SL (1998) Expression of second messenger- and cyclin-dependent protein kinases during postnatal development of rat heart. J Cell Biochem 69:506-521.

Kleitman N, Wood P, Bunge R (1991) Tissue culture methods for the study of myelination. In: Culturing nerve cells (Goslin BA, ed), pp 337-377. Cambridge, MA: MIT.

Koff A, Ohtsuki M, Polyak K, Roberts JM, Massague J (1993) Negative regulation of G1 in mammalian cells: inhibition of cyclin E- dependent kinase by TGF-beta. Science 260:536-539.

Kohn KW (1999) Molecular interaction map of the mammalian cell cycle control and DNA repair systems. Mol Biol Cell 10:2703-2734.

Lemke G, Chao M (1988) Axons regulate Schwann cell expression of the major myelin and NGF receptor genes. Development 102:499-504.

Lemke GE, Brockes JP (1984) Identification and purification of glial growth factor. J Neurosci 4:75-83.

Levi AD, Bunge RP, Lofgren JA, Meima L, Hefti F, Nikolics K, Sliwkowski MX (1995) The influence of heregulins on human Schwann cell proliferation. J Neurosci 15:1329-1340.

Lloyd AC, Obermuller F, Staddon S, Barth CF, McMahon M, Land H (1997) Cooperating oncogenes converge to regulate cyclin/cdk complexes. Genes Dev 11:663-677.

Martin J, Webster H (1973) Mitotic Schwann cells in developing nerve: their changes in shape, fine structure, and axon relationships. Dev Biol 32:417-431.

Martinez LA, Chen Y, Fischer SM, Conti CJ (1999) Coordinated changes in cell cycle machinery occur during keratinocyte terminal differentiation. Oncogene 18:397-406.

Mirsky R, Jessen KR (1996) Schwann cell development, differentiation and myelination. Curr Opin Neurobiol 6: 89-96.

Mirsky R, Jessen KR (1999) The neurobiology of Schwann cells. Brain Pathol 9:293-311.

Monuki ES, Weinmaster G, Kuhn R, Lemke G (1989) SCIP: a glial POU domain gene regulated by cyclic AMP. Neuron 3:783-793.

Morgan D (1997) Cyclin-dependent kinases: engines, clocks and microprocessors. Annu Rev Cell Dev Biol 13:261-291. 
Morrissey TK, Levi AD, Nuijens A, Sliwkowski MX, Bunge RP (1995) Axon-induced mitogenesis of human Schwann cells involves heregulin and p185erbB2. Proc Natl Acad Sci USA 92:1431-1435.

Murphy P, Topilko P, Schneider-Maunoury S, Seitanidou T, Baron-Van Evercooren A, Charnay P (1996) The regulation of Krox-20 expression reveals important steps in the control of peripheral glial cell development. Development 122:2847-2857.

Nakayama K (1998) Cip/Kip cyclin-dependent kinase inhibitors: brakes of the cell cycle engine during development. BioEssays 20:1020-1029.

Pagano M, Pepperkok R, Lukas J, Baldin V, Ansorge W, Bartek J, Draetta G (1993) Regulation of the cell cycle by the cdk2 protein kinase in cultured human fibroblasts. J Cell Biol 121:101-111.

Park SK, Kang SK, Lee DY, Kang MJ, Kim SH, Koh GY (1997) Temporal expressions of cyclins and cyclin dependent kinases during renal development and compensatory growth. Kidney Int 51:762-769.

Pavletich NP (1999) Mechanisms of cyclin-dependent kinase regulation: structures of Cdks, their cyclin activators, and Cip and INK4 inhibitors. J Mol Biol 287:821-828.

Porter S, Clark MB, Glaser L, Bunge RP (1986) Schwann cells stimulated to proliferate in the absence of neurons retain full functional capability. J Neurosci 6:3070-3078.

Ridley AJ, Davis JB, Stroobant P, Land H (1989) Transforming growth factors-beta 1 and beta 2 are mitogens for rat Schwann cells. J Cell Biol 109:3419-3424.

Rieber M, Rieber MS (1994) Cyclin-dependent kinase 2 and cyclin A interaction with E2F are targets for tyrosine induction of B16 melanoma terminal differentiation. Cell Growth Differ 5:1339-1346.

Roberts JM (1999) Evolving ideas about cyclins. Cell 98:129-132.

Salzer JL, Bunge RP (1980) Studies of Schwann cell proliferation. I. An analysis in tissue culture of proliferation during development, Wallerian degeneration, and direct injury. J Cell Biol 84:739-752.

Salzer JL, Williams AK, Glaser L, Bunge RP (1980) Studies of Schwann cell proliferation. II. Characterization of the stimulation and specificity of the response to a neurite membrane fraction. J Cell Biol 84:753-766.
Scherer SS, Salzer JL (1996) Axon-Schwann cell interactions during peripheral nerve degeneration and regeneration. In: Glial cell development, basic principles and clinical relevance (Jessen KR, Richardson WD, eds), pp 165-196. Oxford: Bios Scientific.

Scherer SS, Wang DY, Kuhn R, Lemke G, Wrabetz L, Kamholz J (1994) Axons regulate Schwann cell expression of the POU transcription factor SCIP. J Neurosci 14:1930-1942.

Scherr C, Roberts JM (1995) Inhibitors of mammalian G1 cyclindependent kinases. Genes Dev 79:551-555.

Shiffman D, Brooks EE, Brooks AR, Chan CS, Milner PG (1996) Characterization of the human cyclin-dependent kinase 2 gene. Promoter analysis and gene structure. J Biol Chem 271:12199-12204.

Tanaka T, Tatsuno I, Noguchi Y, Uchida D, Oeda T, Narumiya S, Yasuda T, Higashi H, Kitagawa M, Nakayama K, Saito Y, Hirai A (1998) Activation of cyclin-dependent kinase $2(\mathrm{Cdk} 2)$ in growth-stimulated rat astrocytes. Geranylgeranylated Rho small GTPase(s) are essential for the induction of cyclin $\mathrm{E}$ gene expression. J Biol Chem 273:26772-26778.

Tikoo R, Casaccia-Bonnefil P, Chao M, Koff A (1997) Changes in cyclin-dependent kinase 2 and p27kip1 accompany glial cell differentiation of central glia-4 cells. J Biol Chem 272:442-447.

Turner J, Crossley M (1999) Mammalian Kruppel-like transcription factors: more than just a pretty finger. Trends Biochem Sci 24:236-240.

Wen JY, Morshead CM, van der Kooy D (1994) Satellite cell proliferation in the adult rat trigeminal ganglion results from the release of a mitogenic protein from explanted sensory neurons. J Cell Biol [Erratum (1994) 125:1429] 124:1005-1015.

Wood P, Moya F, Eldridge C, Owens G, Ranscht B, Schachner M, Bunge M, Bunge R (1990) Studies of the initiation of myelination by Schwann cells. Ann NY Acad Sci 605:1-14.

Yan GZ, Ziff EB (1997) Nerve growth factor induces transcription of the p21 WAF1/CIP1 and cyclin D1 genes in PC12 cells by activating the Sp1 transcription factor. J Neurosci 17:6122-6132. 